\title{
The Immunology of Bipolar Disorder
}

\author{
Izabela Guimarães Barbosa ${ }^{a}$ Rodrigo Machado-Vieirac, d Jair C. Soares ${ }^{\mathrm{e}}$ \\ Antonio L. Teixeira ${ }^{a, b}$

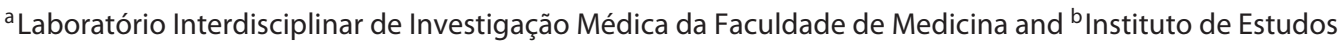 \\ Avançados Transdisciplinares (IEAT), Universidade Federal de Minas Gerais, Belo Horizonte, and \\ 'Laboratório de Neurociências, LIM27, Instituto e Departamento de Psiquiatria, Universidade de São Paulo, \\ São Paulo, Brazil; ${ }^{d}$ Experimental Therapeutics and Pathophysiology Branch, National Institute of Mental Health, \\ National Institutes of Health, Bethesda, Md., and ${ }^{e}$ Department of Psychiatry and Behavioral Sciences, \\ UTHealth Medical School, Houston, Tex., USA
}

\section{Key Words}

Mania · Depression · Aspirin · Interleukin · Lymphocytes ·

Mood disorder

\begin{abstract}
Bipolar disorder (BD) is a psychiatric condition associated with elevated frequency of clinical comorbidities and cognitive impairment. The neurobiology of BD is not completely understood. Recent evidence has implicated immune dysfunction in its physiopathology. Here, we review several data supporting the presence of immunological dysfunction in BD: (i) increased frequency of autoimmune diseases; (ii) distinct immune cell profile; (iii) release of/altered cytokines by stimulated mononuclear cells; (iv) elevated levels of circulating immune markers, and (v) inflammatory changes in the central nervous system. We also discuss the interplay between immunological dysfunction and neuroprogression in BD.
\end{abstract}

(c) 2014 S. Karger AG, Basel

\section{Introduction}

Bipolar disorder (BD) is now regarded as a multisystem condition compromising not only affect or mood, but also cognitive, endocrine, autonomic and sleep functions. BD patients present a high incidence of several medical conditions including cardiovascular and metabolic diseases (particularly diabetes mellitus and obesity), which are associated with a reduced life expectancy [1]. Moreover, BD presents a progressive course characterized by phenomenological changes, cognitive impairment and poor response to pharmacotherapy [2]. The basis for this clinical deterioration of $\mathrm{BD}$, also called 'neuroprogression', seems to be related to changes involving neurobiological mechanisms, including inflammatory and/or immune dysfunction, enhanced oxidative stress, and neurotrophic support breakdown. Indeed, immunological changes occur in BD and they have been identified as a relevant player in the neurobiology of the disease.

Here, we provide a review of the immunological data on $\mathrm{BD}$. We address the immune findings in BD and their association with mood episodes. In addition, we discuss how this immune dysfunction may be related with the neurobiology of $\mathrm{BD}$, focusing on the neuroprogression process.

\section{Evidence of Immune Dysfunction and Pro-Inflammatory State in BD Patients}

\section{Autoimmune Diseases}

The association of autoimmune diseases and autoantibodies with BD has been reported in case report series and epidemiological studies. Patients with autoimmune

\section{KARGER}

E-Mail karger@karger.com

www.karger.com/nim
(C) 2014 S. Karger AG, Basel

1021-7401/14/0213-0117\$39.50/0
Izabela G. Barbosa

Laboratório Interdisciplinar de Investigação Médica da Faculdade de Medicina UFMG, Av. Prof. Alfredo Balena 190, room 281

Santa Efigênia, Belo Horizonte, MG 30130-100 (Brazil)

E-Mail izabelagb@gmail.com 
diseases present a higher risk for $\mathrm{BD}$, while $\mathrm{BD}$ patients exhibit a higher incidence of autoimmune diseases. Eaton et al. [3], in a cohort study, demonstrated that a history of Guillain-Barré syndrome, Crohn's disease and autoimmune hepatitis was associated with greater risk for BD. Systemic lupus erythematosus women present a 6-fold increase in the incidence of BD [4], while multiple sclerosis patients present up to a 30 -fold increase [5]. It is widely recognized that $\mathrm{BD}$ patients present a higher frequency of autoimmune thyroiditis [6]. It is worth emphasizing that this increased occurrence of autoimmune thyroiditis and also anti-thyroid peroxidase antibodies in BD patients are not explained by lithium exposure [6].

The offspring of BD patients also inherit this vulnerability to autoimmune thyroiditis, suggesting an epigenetic autoimmune susceptibility [7]. Together these findings suggest a link between autoimmunity and $\mathrm{BD}$.

\section{Immune Cells Phenotype in $B D$}

Based on the very first evidence of leukocyte changes in major depression, some researchers evaluated the total number and subpopulations of white blood cells from $\mathrm{BD}$ patients. One study showed a reduction of neutrophils in depressed BD patients [8]. A decrease in the total number of lymphocytes during mania was also demonstrated [9]. Just recently, the evaluation of leukocytes in $\mathrm{BD}$ patients with flow cytometry to assess phenotype-specific cell surface markers in order to quantify monocytes and lymphocyte subsets (B cells, T cells, T helper cells and $\mathrm{T}$ suppressor/cytotoxic cells) has been conducted.

These new studies have shown that the frequency of monocytes (CD14+), B cells (CD19+) or NK cells is the same in $\mathrm{BD}$ patients and healthy controls $[10,11]$. The following findings have been made regarding different T cell subsets: (i) BD patients do not present differences in $\mathrm{T}$ cytotoxic cells (CD8+) or $\mathrm{T}$ helper cells $(\mathrm{CD} 4+)$ [11]; (ii) BD patients do not present differences in activated T lymphocytes (expressing CD25+), but these cells were less sensitive to dexamethasone effects when compared to controls [12], and (iii) BD patients present a reduction in the frequency of $\mathrm{T}$ regulatory lymphocytes $(\mathrm{CD} 4+\mathrm{CD} 25+\mathrm{Foxp} 3+)$ [10], a cellular type related with the suppression of the proliferation of effector $\mathrm{T}$ cells and the inhibition of the development of autoimmune diseases. This last finding may partially explain the association of $\mathrm{BD}$ with autoimmune diseases as shown above.
In vitro Cytokine Production by Mononuclear Cells from BD Patients

In whole-blood assays, Kim et al. [13] found increased levels of interleukin-6 (IL-6) and tumor necrosis factor (TNF)- $\alpha$ following phytohemagglutinin and lipopolysaccharide stimuli, but no change in the production of the IL-2 and interferon (IFN)- $\gamma$. Studies evaluating the release of cytokines by stimulated lymphocytes suggest lower production of IL-2 $[14,15]$ and IFN- $\gamma[14,15]$ in BD patients, with no difference in IL-4 [14] and IL-1 $\beta$ [16]. Data regarding the production of IL-6 $[15,16]$ and IL-10 $[14,15]$ are contradictory, with some studies showing decreased production of IL- 6 and IL-10 [15], and others no significant differences $[14,16]$.

BD patients, including children, present an increased monocyte phagocytic activity $[17,18]$. The reason for this is not clear, but some hypotheses to explain this phenomenon are: (i) the illness per se induces a state of hyperactivity of monocytes (e.g. the stress state caused by the illness can induce activation of monocytes); (ii) the state of hyperactivity of monocytes could represent a key factor in the development of $\mathrm{BD}$; (iii) there is an underlying factor that independently influences the development of BD illness and the hyperactivity of monocytes, and (iv) there are two underlying factors, unrelated, sharing the same environment and leading to the activation of monocytes and BD illness.

\section{Circulating Levels of Immune Markers}

The presence of immunological activation in $\mathrm{BD}$ has also been evaluated through circulating levels of cytokines. In contrast to findings on stimulated mononuclear cells, there is consistent evidence of increased levels of a series of cytokines in $\mathrm{BD}$. When compared with controls, BD patients present increased circulating levels of the Th2-related cytokines IL-4 and IL-10 [19]. BD patients also present a trend towards increased levels of pro-inflammatory cytokines like IL-1 $\beta$ and IL-6 [19]. Interestingly, the levels of TNF- $\alpha$, a prototypical pro-inflammatory cytokine, were comparable in BD patients and healthy controls [19-23]. Conversely, studies have consistently demonstrated increased levels of the soluble receptor of TNF- $\alpha$ type 1 , sTNFR1, in BD $[19,21,23]$. sTNFR1 is the circulating form of TNFR1, a receptor with a ubiquitous distribution that is responsible for most of the actions of TNF- $\alpha$. As sTNFR1 is induced by TNF- $\alpha$, its measurement is useful to determine the overall production of TNF- $\alpha$ [22].

Additional studies have extended observations of cytokines to other immune markers that are also related to the increased inflammatory activity in $\mathrm{BD}$. In comparison 
with healthy controls, BD patients present increased levels of: (i) the soluble IL-2 receptor, $\operatorname{sIL} 2 \mathrm{R}[19,20]$ - the interaction of IL-2 and its receptor plays a central role in the signal transduction pathways resulting in cell proliferation and clonal expansion of activated T cells; (ii) the IL-1 receptor antagonist, IL1ra [19], a soluble receptor that naturally inhibits the pro-inflammatory effect of IL$1 \beta$; (iii) chemokines - chemotactic cytokines classically responsible for directing the movement of circulating leukocytes to sites of inflammation [24]; (iv) markers of endothelial cell activation, such as osteoprotegerin and von Willebrand factor [24]; (v) adipokines - mediators produced by the adipose tissue [21]; (vi) oxidative stress markers, such as thiobarbituric acid-reactive substances, and antioxidant enzyme activity (superoxide dismutase and catalase) [25], and (vii) acute-phase proteins, such as C-reactive protein [26], among others. Despite clear evidence demonstrating an inflammatory status in $\mathrm{BD}$ patients, not all inflammation-associated biomarkers are elevated in BD [27].

\section{Clinical and Neuropathological Correlates of Peripheral Inflammation in BD}

$\mathrm{BD}$ is characterized by the recurrence of mood episodes. Clinical and epidemiological studies have revealed that genetic background, stressful life events (such as childhood maltreatment) or substance abuse are related to the risk of development of mood disorders, particularly BD. It is hypothesized that the first mood episodes are initially triggered mainly through stressful events. During the course of $\mathrm{BD}$, mood relapses may emerge spontaneously, leading to neuroprogression in which the higher the frequency of mood episodes, the worse the prognosis of $\mathrm{BD}$ becomes [2].

In this scenario, mood episodes seem to play a pivotal role acting as a major 'toxic player' in the neuroprogression of the illness $[2,28]$. One of the possible mechanisms responsible for the neuroprogression is the aberrant exacerbation of the pro-inflammatory cytokines and other inflammatory markers during mood episodes (i.e. mania or bipolar depression) in BD. Meta-analyses and casecontrol studies have shown that BD patients in mania present increased levels of IL-6, IL-10, TNF- $\alpha$, sTNFR1, chemokines and sIL2R in comparison with not only healthy controls but also BD patients in euthymia [1922 ]. These findings indicate that the pro-inflammatory state in BD patients is strongly enhanced during mood episodes. Corroborating the hypothesis of mood episodes

Immunology of BD as a major 'toxic player', some studies positively correlated the severity of mood episodes with the levels of proinflammatory markers $[23,28]$. It is worth mentioning that there is a lack of studies assessing cytokines and other inflammatory markers in BD patients during depression episodes.

Pro-inflammatory cytokines are relatively large molecules that are not able to freely cross the blood-brain barrier under physiological conditions. Some of the pathways possibly involved in the signaling process of peripheral cytokines in the central nervous system (CNS) are: (i) passage through leaky regions in the blood-brain barrier; (ii) active transport via saturable transport molecules; (iii) activation of endothelial cells and other cell types lining the cerebral vasculature, and (iv) binding to cytokine receptors associated with peripheral afferent nerve fibers (e.g. the vagus nerve) that then relay cytokine signals to relevant CNS regions. Once the peripheral cytokine signals reach the CNS, a complex network composed of neurons and glial elements amplifies the effect through production of cytokines and increased expression of cytokine receptors. Of particular relevance to this translating process from the periphery to the CNS is the activation of microglia. Microglial cells are developed from the same progenitors as tissue and blood macrophages, and usually exist in a quiescent state. A microglial cell can undergo activation, increasing the expression of cytokines and activation-associated surface molecules, and may directly injure neurons. The evidence of microglial activation in $\mathrm{BD}$ comes from postmortem investigations, while in vivo studies (e.g. PET neuroimaging) are lacking.

A single study assessed pro-inflammatory cytokines in the cerebrospinal fluid of BD patients, reporting increased IL- $1 \beta$ levels indicating that the pro-inflammatory status does not occur only in the periphery, but also in the CNS [29]. In line with this, postmortem studies have shown that BD patients present increased markers of neuroinflammation and decreased anti-inflammatory markers in the frontal cortex in comparison with controls [30, 31]. Specifically, increased protein and mRNA levels of IL- $1 \beta$ and its receptor, IL-1R, were described, as well as upregulation of nuclear factor-kappa B (NF- $\kappa B$ ) transcription factor subunits (p50 and p65), and astroglial and microglial markers (glial fibrillary acidic protein, inducible nitric oxide synthase, c-Fos and CD11b) in the prefrontal cortex of BD [30]. Moreover, BD patients present decreased total RNA expression of TGF- $\beta$ in the frontal cortex area [31]. Dean et al. [32] showed that BD patients present increased transmembrane TNF- $\alpha$ protein levels in the anterior cingulate area, and decreased TNFR2 protein levels in the 
dorsolateral prefrontal cortex. These data reinforce a role for cytokines in BD as the dorsolateral prefrontal and anterior cingulate cortex are well known to be critically involved in mood regulation and cognitive processes compromised in the illness.

In the CNS, physiological levels of pro-inflammatory cytokines, such as IL-1, IL- 6 and TNF- $\alpha$, are involved in neural processes like the induction and maintenance of long-term potentiation, neurogenesis, regulation of the survival of differentiated neurons and the development of astrocytes, impacting on several cognitive (e.g. memory) functions [33, 34]. However in response to several insults (i.e. ischemia, trauma, 'neurotoxicity') cytokines may contribute to the neurodegenerative process. For instance, increased levels of TNF- $\alpha$ seem to be involved in neuronal cell death through the activation of caspases and apoptotic machinery [35]. This neurodegenerative process mediated by TNF- $\alpha$ may contribute to the volumetric reduction and hypoactivation of frontal lobes in $\mathrm{BD}$ patients [36] with associated disinhibition of limbic structures [37]. In line with this, our group demonstrated that circulating TNF- $\alpha$ levels correlated with inhibitory control in BD patients [38]. The impairment in inhibitory response is regarded as a cognitive endophenotype of $\mathrm{BD}$.

In summary, there is mounting evidence of increased immune markers, particularly pro-inflammatory cytokines, in the periphery and in the CNS of BD patients. However, it is still uncertain if and how the peripheral changes in $\mathrm{BD}$ may reflect pro-inflammatory processes that primarily occur in the CNS. Alternatively, the peripheral changes in $\mathrm{BD}$ patients could influence neural activity in the CNS, deflagrating mood episodes.

\section{Stress: A Missing Link between IIIness and Inflammation in BD?}

It is well known that mood episodes in BD can be precipitated by exposure to stress, resulting in the release of glucocorticoid hormones, such as cortisol. In physiological conditions, cortisol exerts an inhibitory effect on cytokine production by immune cells. During chronic stress, however, this inhibitory effect is lost. Continuous release of pro-inflammatory cytokines, particularly IL$1 \beta$, causes the activation of intracellular pathways (including mitogen-activated protein kinase, MAPK, pathways), inhibiting the glucocorticoid receptor response to cortisol. The suppression of glucocorticoid receptor by cytokines may also contribute to the persistent elevated levels of cortisol during chronic stress [39].
Abnormal activation of the hypothalamic-pituitaryadrenal (HPA) axis in BD has been reported. For instance, euthymic BD patients exhibit blunted stress response as shown by reduced heart rate and salivary cortisol levels when exposed to acute stress [40]. In parallel to this altered neuroendocrine response, these patients present reduced lymphocyte sensitivity to glucocorticoids [40]. This HPA axis dysfunction in BD patients may indicate a defective neuroendocrine control over the immune system explaining, at least partially, why $\mathrm{BD}$ patients present increased circulating levels of pro-inflammatory cytokines. As mood episodes may trigger stress responses, a cyclical abnormal activation of the HPA axis may take place, leading to chronic increased levels of inflammatory markers and, hence, allostatic load in BD.

Glucocorticoids regulate not only immunity, but also other functions such as metabolism. Glucocorticoid excess, secondary to HPA activation, leads to metabolic dysfunction and central obesity in BD. The related medical comorbidities also contribute to higher levels of stress perpetuating HPA axis activation. Therefore, the increased pro-inflammatory status in $\mathrm{BD}$ patients may be one of the consequences of the increased rates of chronic medical illness. It seems unlikely that medical clinical comorbidities explain completely the increased pro-inflammatory state found in BD. In accordance with this, overweight $\mathrm{BD}$ patients present an increased pro-inflammatory state when compared with overweight controls [21].

\section{Immune-Based Strategies in BD}

The development of new therapeutic targets for BD is of paramount importance, since the current pharmacological strategy is not fully effective to treat and/or prevent the relapses of mood episodes. Moreover, the available drugs do not treat the clinical comorbidities associated with $\mathrm{BD}$; on the contrary, they can even make them worse (e.g. weight gain).

The immune system seems to be a promising target. Nery et al. [41] conducted a double-blind, randomized, placebo-controlled add-on study in depressive or mixed episodes of BD with a cyclooxygenase 2 inhibitor (celecoxib). In this study the addition of celecoxib to the standard treatment was associated with a faster improvement of depressive symptoms in comparison to the standard treatment alone [41]. This study indicated a potential antidepressant effect of anti-inflammatory drugs. New studies evaluating other anti-inflammatory (i.e. Aspirin) or immune-based (i.e. minocycline) strate- 
gies in $\mathrm{BD}$ patients are in progress $[42,43]$. It is worth mentioning case-reports of mania in patients under treatment with infliximab, an anti-TNF- $\alpha$ monoclonal antibody $[44,45]$, corroborating the view that it is possible to modulate mood and mood disorders by using immune mediators.

\section{Conclusion}

A higher frequency of autoimmune diseases, activation of cell-mediated immunity and systemic inflammation are observed in $\mathrm{BD}$. This pro-inflammatory profile experienced by BD patients may have deleterious conse- quences, acting as a major player in disease neuroprogression. Conversely, this immune imbalance can be regarded as a promising target for the development of more effective pharmacological strategies in BD.

\section{Acknowledgments}

This work was partly funded by CNPq and Fapemig, Brazil. Jair C. Soares was partly supported by the Pat R. Rutherford Jr. Chair in Psychiatry, Department of Psychiatry and Behavioral Sciences, UTHealth Medical School, and also by the Stanley Medical Research Institute. Dr. Barbosa is recipient of a CAPES scholarship. Dr. Machado-Vieira would like to thank Sao Paulo Research Foundation, Brazil and National Institute of Mental Health, USA.

\section{References}

1 Fajutrao L, Locklear J, Priaulx J, Heyes A: A systematic review of the evidence of the burden of bipolar disorder in Europe. Clin Pract Epidemiol Ment Health 2009;23:1-8.

$\checkmark 2$ Berk M, Kapczinski F, Andreazza AC, Dean OM, Giorlando F, Maes M, Yücel M, Gama CS, Dodd S, Dean B, Magalhães PV, Amminger P, McGorry P, Malhi GS: Pathways underlying neuroprogression in bipolar disorder: focus on inflammation, oxidative stress and neurotrophic factors. Neurosci Biobehav Rev 2011;35:804-817.

-3 Eaton WW, Pedersen MG, Nielsen PR, Mortensen PB: Autoimmune diseases, bipolar disorder, and non-affective psychosis. Bipolar Disord 2010;12:638-646.

4 Bachen EA, Chesney MA, Criswell LA: Prevalence of mood and anxiety disorders in women with systemic lupus erythematosus. Arthritis Rheum 2009;61:822-829.

5 Edwards LJ, Constantinescu CS: A prospective study of conditions associated with multiple sclerosis in a cohort of 658 consecutive outpatients attending a multiple sclerosis clinic. Mult Scler 2004;10:575-581.

-6 Kupka RW, Nolen WA, Post RM, McElroy SL, Altshuler LL, Denicoff KD, Frye MA, Keck PE Jr, Leverich GS, Rush AJ, Suppes T, Pollio C, Drexhage HA: High rate of autoimmune thyroiditis in bipolar disorder: lack of association with lithium exposure. Biol Psychiatry 2002;51:305-311.

7 Hillegers MH, Reichart CG, Wals M, Verhulst FC, Ormel J, Nolen WA, Drexhage HA: Signs of a higher prevalence of autoimmune thyroiditis in female offspring of bipolar parents. Eur Neuropsychopharmacol 2007; 17:394399.

-8 Darko DF, Rose J, Gillin JC, Golshan S, Baird SM: Neutrophilia and lymphopenia in major mood disorders. Psychiatry Res 1988;25:243251.
-9 Abeer, El-Sayed A, Ramy HA: Immunological changes in patients with mania: changes in cell mediated immunity in a sample from Egyptian patients. Egypt J Immunol 2006;13: 79-85.

10 do Prado CH, Rizzo LB, Wieck A, Lopes RP, Teixeira AL, Grassi-Oliveira R, Bauer ME: Reduced regulatory $\mathrm{T}$ cells are associated with higher levels of Th1/TH17 cytokines and activated MAPK in type 1 bipolar disorder. Psychoneuroendocrinology 2013;38:667-676.

-11 Drexhage RC, Hoogenboezem TH, Versnel MA, Berghout A, Nolen WA, Drexhage HA: The activation of monocyte and $\mathrm{T}$ cell networks in patients with bipolar disorder. Brain Behav Immun 2011;25:1206-1213.

12 Knijff EM, Breunis MN, van Geest MC, Kupka RW, Ruwhof C, de Wit HJ, Nolen WA, Drexhage HA: A relative resistance of T cells to dexamethasone in bipolar disorder. Bipolar Disord 2006;8:740-750.

13 Kim YK, Jung HG, Myint AM, Kim H, Park $\mathrm{SH}$ : Imbalance between pro-inflammatory and anti-inflammatory cytokines in bipolar disorder. J Affect Disord 2007;104:91-95.

14 Liu HC, Yang YY, Chou YM, Chen KP, Shen WW, Leu SJ: Immunologic variables in acute mania of bipolar disorder. J Neuroimmunol 2004;150:116-122.

-15 Boufidou F, Nikolaou C, Alevizos B, Liappas IA, Christodoulou GN: Cytokine production in bipolar affective disorder patients under lithium treatment. J Affect Disord 2004;82: 309-313.

16 Knijff EM, Breunis MN, Kupka RW, de Wit HJ, Ruwhof C, Akkerhuis GW, Nolen WA, Drexhage HA: An imbalance in the production of IL- $1 \beta$ and IL- 6 by monocytes of bipolar patients: restoration by lithium treatment. Bipolar Disord 2007;9:743-753.
17 McAdams C, Leonard BE: Neutrophil and monocyte phagocytosis in depressed patients. Prog Neuropsychopharmacol Biol Psychiatry 1993;17:971-984.

18 Padmos RC, Hillegers MH, Knijff EM, Vonk R, Bouvy A, Staal FJ, de Ridder D, Kupka RW, Nolen WA, Drexhage HA: A discriminating messenger RNA signature for bipolar disorder formed by an aberrant expression of inflammatory genes in monocytes. Arch Gen Psychiatry 2008;65:395-407.

19 Modabbernia A, Taslimi S, Brietzke E, Ashrafi M: Cytokine alterations in bipolar disorder: a meta-analysis of 30 studies. Biol Psychiatry 2013;74:15-25.

20 Munkholm K, Braüner JV, Kessing LV, Vinberg M: Cytokines in bipolar disorder vs. healthy control subjects: a systematic review and meta-analysis. J Psychiatr Res 2013;47: 1119-1133.

-21 Barbosa IG, Rocha NP, de Miranda AS, Magalhães PV, Huguet RB, de Souza LP, Kapczinski F, Teixeira AL: Increased levels of adipokines in bipolar disorder. J Psychiatr Res 2012;46:389-393.

22 Barbosa IG, Huguet RB, Mendonça VA, Sousa LP, Neves FS, Bauer ME, Teixeira AL: Increased plasma levels of soluble TNF receptor I in patients with bipolar disorder. Eur Arch Psychiatry Clin Neurosci 2011;261:139-143.

23 Hope S, Dieset I, Agartz I, Steen NE, Ueland T, Melle I, Aukrust P, Andreassen OA: Affective symptoms are associated with markers of inflammation and immune activation in bipolar disorders but not in schizophrenia. J Psychiatr Res 2011;45:1608-1616.

24 Barbosa IG, Rocha NP, Bauer ME, de Miranda AS, Huguet RB, Reis HJ, Zunszain PA, Horowitz MA, Pariante CM, Teixeira AL: Chemokines in bipolar disorder: trait or state? Eur Arch Psychiatry Clin Neurosci 2013;263: 159-165. 
-25 Machado-Vieira R, Andreazza AC, Viale CI, Zanatto V, Cereser V Jr, da Silva Vargas R, Kapczinski F, Portela LV, Souza DO, Salvador $\mathrm{M}$, Gentil V: Oxidative stress parameters in unmedicated and treated bipolar subjects during initial manic episode: a possible role for lithium antioxidant effects. Neurosci Lett 2007;421:33-36.

-26 Tsai SY, Chung KH, Wu JY, Kuo CJ, Lee HC, Huang SH: Inflammatory markers and their relationships with leptin and insulin from acute mania to full remission in bipolar disorder. J Affect Disord 2012;136:110-116.

- 27 Barbosa IG, Pessoa Rocha N, Huebra L, Oliveira C, Nobre V, Teixeira AL: Not all inflammatory biomarkers are elevated in bipolar disorder: evidence for procalcitonin. Biol Psychiatry 2013;74:e29-e30.

28 Kapczinski F, Dal-Pizzol F, Teixeira AL, Magalhaes PV, Kauer-Sant'Anna M, Klamt F, Pasquali MA, Quevedo J, Gama CS, Post R: A systemic toxicity index developed to assess peripheral changes in mood episodes. Mol Psychiatry 2010;15:784-786.

29 Söderlund J, Olsson SK, Samuelsson M, Walther-Jallow L, Johansson C, Erhardt S, Landén M, Engberg G: Elevation of cerebrospinal fluid interleukin- $1 \beta$ in bipolar disorder. J Psychiatry Neurosci 2011;36:114-118.

30 Rao JS, Harry GJ, Rapoport SI, Kim HW: Increased excitotoxicity and neuroinflammatory markers in postmortem frontal cortex from bipolar disorder patients. Mol Psychiatry 2010;15:384-392.
31 Bezchlibnyk YB, Wang JF, McQueen GM, Young LT: Gene expression differences in bipolar disorder revealed by cDNA array analysis of post-mortem frontal cortex. J Neurochem 2001;79:826-834.

32 Dean B, Gibbons AS, Tawadros N, Brooks L, Everall IP, Scarr E: Different changes in cortical tumor necrosis factor- $\alpha$-related pathways in schizophrenia and mood disorders. Mol Psychiatry 2013;18:767-773.

33 Eyre H, Baune BT: Neuroplastic changes in depression: a role for the immune system. Psychoneuroendocrinology 2012;37:13971416.

34 Khairova RA, Machado-Vieira R, Du J, Manji HK: A potential role for pro-inflammatory cytokines in regulating synaptic plasticity in major depressive disorder. Int J Neuropsychopharmacol 2009;12:561-578.

35 Cacci E, Claasen JH, Kokaia Z: Microglia-derived tumor necrosis factor- $\alpha$ exaggerates death of newborn hippocampal progenitor cells in vitro. J Neurosci Res 2005;80:789-797.

-36 Kupferschmidt DA, Zakzanis KK: Toward a functional neuroanatomical signature of bipolar disorder: quantitative evidence from the neuroimaging literature. Psychiatry Res 2011; 193:71-79.

-37 Brooks JO 3rd, Wang PW, Bonner JC, Rosen AC, Hoblyn JC, Hill SJ, Ketter TA: Decreased prefrontal, anterior cingulate, insula, and ventral striatal metabolism in medicationfree depressed outpatients with bipolar disorder. J Psychiatr Res 2009;43:181-188.

38 Barbosa IG, Rocha NP, Huguet RB, Ferreira RA, Salgado JV, Carvalho LA, Pariante CM, Teixeira AL: Executive dysfunction in euthymic bipolar disorder patients and its association with plasma biomarkers. J Affect Disord 2012;137:151-155.
9 Jones KA, Thomsen C: The role of the innate immune system in psychiatric disorders. Mol Cell Neurosci 2013;53:52-62.

40 Wieck A, Grassi-Oliveira R, Prado CH, Rizzo LB, Oliveira AS, Kommers-Molina J, Viola TW, Teixeira AL, Bauer ME: Differential neuroendocrine and immune responses to acute psychosocial stress in women with type 1 bipolar disorder. Brain Behav Immun 2013;34: 47-55.

41 Nery FG, Monkul ES, Hatch JP, Fonseca M, Zunta-Soares GB, Frey BN, Bowden CL, Soares JC: Celecoxib as an adjunct in the treatment of depressive or mixed episodes of bipolar disorder: a double-blind, randomized, placebo-controlled study. Hum Psychopharmacol 2008;23:87-94.

42 Berk M, Dean O, Drexhage H, McNeil JJ, Moylan S, Oneil A, Davey CG, Sanna L, Maes M: Aspirin: a review of its neurobiological properties and therapeutic potential for mental illness. BMC Med 2013;11:74.

43 Savitz J, Preskorn S, Teague TK, Drevets D, Yates W, Drevets W: Minocycline and aspirin in the treatment of bipolar depression: a protocol for a proof-of-concept, randomised, double-blind, placebo-controlled, $2 \times 2$ clinical trial. BMJ Open 2012;2:e000643.

44 Austin M, Tan YC: Mania associated with infliximab. Aust NZ J Psychiatry 2012;46:684685 .

45 Elisa B, Beny L: Induction of manic switch by the tumour necrosis factor-alpha antagonist infliximab. Psychiatry Clin Neurosci 2010;64: 442-443. 